\title{
Hcc Angiogenic Propriety and Tumor Recurrence in Liver Transplant Recipients
}

\author{
Otto WJ1*, Hołówko WH¹, Krawczyk MS ${ }^{1}$, Król MA², Wilkowojska UM², Wilczek E³ and Sierdziński J4 \\ ${ }^{1}$ Department of General, Transplant and Liver Surgery, Central Teaching Hospital, Medical University of Warsaw, Poland \\ ${ }^{2}$ Department of Oncology, Haematology and Internal Medicine, Central Teaching Hospital, Medical University of Warsaw, Poland \\ ${ }^{3}$ Department of Pathology, Central Teaching Hospital, Medical University of Warsaw, Poland \\ ${ }^{4}$ Department of Medical Informatics and Telemedicine, Central Teaching Hospital, Medical University of Warsaw, Poland
}

\begin{abstract}
Objective: Clinic-pathologic characteristic of hepatocellular carcinoma are mostly accounting for the tumor recurrence after liver transplantation. It is assumed that tumor angiogenesis capability contributes to the rates of post-transplant relapse, as well. The aim of study was to evaluate the contribution of the circulating hematopoietic stem cells (HSCs); endothelial progenitor cells (EPCs) and serum vascular endothelial growth factor (VEGF) to the recurrence of HCC after liver transplantation.
\end{abstract}

Methods: The study was carried out on 49 cirrhotic patients with HCC within the Milan criteria. They were transplanted in 2009 and followed-up for 54 months, so far. The rates of circulating HSCs and EPCs were assessed through a phenotypic analysis of $2 \mathrm{ml}$ of fresh blood in a flow cytometer. Serum VEGF concentration was measured by enzyme-linked immunoassay (ELISA). Histopathology examination of the liver explants was performed for tumor characteristic. The data were analyzed with statistical tests.

Results: There were 9 deaths related to the procedure. Of 40 remaining patients the tumor recurred in $6(15 \%)$ prior to 36 months and then in $5(12.5 \%)$ prior to 54 months of observation. The pre-transplant rates of circulating HSCs and EPCs were significantly higher in patients with tumor relapse; Chisq $=17.25, p<0.001$ and Chisq=13.96, $p<0.001$, respectively. The differences in the serum VEGF concentration were not significant in this group, however.

Conclusion: Tumor angiogenesis capability should be considered as the predictive factor of tumor relapse after liver transplantation.

Keywords: Hepatocellular carcinoma recurrence; Angiogenesis; Hematopoietic stem cells; Endothelial progenitor cells; Vascular endothelial growth factor; Liver transplantation

\section{Introduction}

Liver transplantation for the treatment of hepatocellular carcinoma (HCC) is an attractive option in patients with liver cirrhosis [1-4]. Poor tumor differentiation and microvascular invasion are the main factors indicating the unfavorable tumor biology and the probability of an early tumor relapse after liver transplantation [5]. Unfortunately, no accurate clinical predictors of the tumor biology have been established, yet [6-8].

Angiogenesis is indicated as one of possible mechanisms that conditions the propriety of hepatocellular carcinoma [9-13]. The endothelial progenitor cells (EPCs) and the hematopoietic stem cells (HSCs) play a significant role in tumor angiogenesis. The HSCs can be identified as the cells that simultaneously express the cell surface markers CD45, CD34, CD133 and the EPCs are the fraction of HSCs that express additionally the cell surface marker CD309. Some reports indicate that the tumor angiogenesis capability correlates with the disease progression, distant metastasis and the recurrence of the tumor after radical surgical treatment. It is also suggested that identification of angiogenesis biomarkers could be useful for clinical evaluation, for selection of patients to the treatment options and for prediction of the disease recurrence [14-18].

The purpose of this study was to evaluate the expression levels of circulating endothelial progenitor cells and the serum VEGF concentration and the contribution of these factors to the recurrence of HCC after liver transplantation.

\section{Review of Literature}

Liver transplantation is an attractive option for HCC treatment because it allows to achieve radical elimination of the tumor and the underlying liver disease, simultaneously. The rate of the long-time survival, especially in patients with tumor within the Milan criteria, approximates the survival of the transplanted for non-malignant indications [1-7]. According to the experience of our Department, the tumor relapse at the 5-year follow-up did not exceed $25 \%$ and the rate of 5-year overall survival approximated up to $70 \%$.The most common cause of deaths is HCC relapse [3-7]. Though, the indubitable effects of the procedure are frustrated by the tumor recurrence in the transplanted liver.

There are at least several patient- and tumor-related factors responsible for the recurrence of HCC after liver transplantation. The $\mathrm{C}$ hepatitis virus is one of the most important. Patients with $\mathrm{HCV}$ infection are known to have higher recurrence rate [1].They

*Corresponding author: Włodzimierz Otto, Professor of Surgery, Dept. General Transplant and Liver Surgery, Central Teaching Hospital, Medical University of Warsaw,Banacha 1a, Warsaw, Poland,Tel: +48 22599 2546, +48 602671 176; E-mail:wotto@wum.edu.pl

Received December 22, 2014; Accepted February 19, 2015; Published February 26, 2015

Citation: Otto WJ, Hołówko WH, Krawczyk MS, Król MA, Wilkowojska UM, et al. (2015) Hcc Angiogenic Propriety and Tumor Recurrence in Liver Transplant Recipients. Pharm Anal Acta 6: 343. doi:10.4172/2153-2435.1000343

Copyright: $\odot 2015$ Otto WJ, et al. This is an open-access article distributed under the terms of the Creative Commons Attribution License, which permits unrestricted use, distribution, and reproduction in any medium, provided the original author and source are credited. 
tend to have more advanced tumors at the first medical presentation and certainly, they have a worse underlying liver disease [1-3,19,20]. The active $\mathrm{C}$ hepatitis following liver transplantation and elevated postoperative levels of transaminase were shown in many reports as independent risk factors for HCC recurrence $[5,19]$.

The tumor-related factors include tumor number, size, location, histologic grade of differentiation, and presence of macro and microvascular invasion and extrahepatic spread of the disease [24,19,21-24]. The grade of tumor differentiation and the tumor histological type are the universally accepted criteria used to classify HCC. A numerous meta-analysis showed significant correlation of tumor recurrence and poor tumor differentiation [5,6,9,12]. There is also clear evidence that the less differentiated tumor is, the higher the risk of vascular invasion to the surrounding liver tissue $[19,25]$. It also seems proven that vascular invasion is a prerequisite to tumor dissemination and is known to be the strongest predictor of tumor relapse in the transplant recipients $[3,7,8,21,26,27]$.

There is no standard method of identifying the unfavorable tumor biology likely to entail a high risk for tumor recurrence[10,21,26]. Histologic information on tumor characteristic is available no sooner than at the time of the pathologic examination of the explanted liver. The needle biopsy could be implicated in selected casesbecausemany tumors are not suitable for biopsy and there is a risk for cancer cell seeding during the procedure $[6,12,15,23]$.

Angiogenesis seems to play the crucial role in tumor development and growth $[9,10,23,28]$. Many reports indicate the hematopoietic and endothelial precursor cells as the main timber of tumor angiogenesis. It is believed that the cells are mobilized from the bone marrow stromal cells by tumor-derived systemically circulating cytokines such as the vascular endothelial growth factor (VEGF) and they are used in the process of neovascularization during all stages of tumor development [27-29]. The combination of HSCs and EPCs was shown to be essential for neovascularization in animal models [14-18]. Many studies support the suggestion that the levels of stem/progenitor cell correspond to the stage of HCC development and may help in disease monitoring and outcome predicting. Ho et al. [13] found the circulating EPCs levels significantly elevated in patients with advanced HCC. Lyden et al. [17] and Beerepoot et al. [14] showed that the combination of hematopoietic stem cells (HSCs) and endothelial progenitor cells (EPCs) is essential for tumor growth. The clinical data gathered by Yang et al. [26] show that the level of circulating EPCs is significantly higher in HCC patients than in patients with cirrhosis and normal subjects. Recently, Xi-Tai Sun et al. [30] demonstrated that the role of EPCs in neovascularization becomes more important as HCC growth progresses, and Zhu et al. [25] revealed that the EPCs are mobilized and incorporated into tumor vessels throughout the whole process of HCC growth.The reportsquoted above suggestthat tumor angiogenesis propriety should be considered as the important risk factor of tumor recurrence in liver transplant recipients for HCC.

\section{Methods and Materials}

The program for liver transplantation started at the Department of General, Transplant and Liver Surgery, Medical University of Warsaw, Poland, in 2001. Up to the end of 2009, there were 775 liver transplantations performed in 745 patients; in 156 patients the procedure was undertaken due to liver cirrhosis and hepatocellular carcinoma. This study covereda selected group of 49 patients (F17, M32, median age 58 years) with liver cirrhosis who had hepatocellular carcinoma within the Milan criteria and were transplanted in 2009.
The study constitutes part of research projects granted by the National Science Center (Grant No. E/154) and was approved by the Bioethics Committee of Warsaw Medical University.

In $38(77.5 \%)$ patients liver cirrhosis developed due to HCV infection, but 9 of them had the component of alcoholic liver disease (ALD), as well. Eleven patients (22.5\%) had liver cirrhosis due to HBV infection.HCC was diagnosed pre-operatively by characteristic appearance on radiologic imaging studies that confirmed a single lesion $</=5 \mathrm{~cm}$ in $27(55.1 \%)$, and up to three separate lesions, not larger than $3 \mathrm{~cm}$ in $22(44.9 \%)$. No evidence of gross vascular invasionand no regional nodes or distant metastases were present. None of the patients had been pretreated for HCC but all presented with a history of treatment for liver dysfunction and portal hypertension; 35 (71.4\%) patients were clinically evaluated as belonging to Group Aand $14(28.6 \%)$ to Group B according to the Child-Pugh classification.The on-explant histopathology analysis confirmed that they had a cirrhotic liver and HCC within the Milan criteria.HCC appeared to be well, moderately and poorlydifferentiated in $10(20 \%), 31(6 \%)$ and $9(17 \%)$ patients, respectively.Micro vascular invasion of $\mathbf{H C C}$ was present in $11(22.4 \%)$ cases. The mean serum alpha-fetoprotein (AFP) for all 49 patients was $1233.32 \mathrm{ng} / \mathrm{mL}, \mathrm{SD} \pm 3292,1(287.7-2178.995 \% \mathrm{CI})$, and mean platelets count was $83 \times 10^{3} / \mathrm{mcL}, \mathrm{SD} \pm 42.8\left(71.1-95.7 \times 10^{3} 95 \% \mathrm{CI}\right)$.The mean pre-transplant rate of the hematopoietic stem cells (\%HSCs) was 0.015 , $\mathrm{SD} \pm 0.008(0.0128-0.01795 \% \mathrm{CI})$, the mean rate of the endothelial progenitor cells (\%EPCs/HSCs) was 3.468, SD \pm 1.084 (3.156-3.779 95\% $\mathrm{CI}$ ), and the mean level of serum VEGF concentration was $317.464 \mathrm{pg} /$ $\mathrm{mL}, \mathrm{SD} \pm 241.97$ (247.96-386.96 95\% CI). All patients transplanted for HCC received immunosuppressive therapy with calcineurin inhibitors, anti-metabolites and corticosteroids. They were followed continuously for 54 months (so far), undergoing routine clinical examination and USG examination every 3-6 months.Suspicious lesions were confirmed by computed tomography (CT) in every case.

\section{Assessment of circulating endothelial progenitorcells}

The evaluation of the circulating hematopoietic and endothelial progenitor cells and quantitative determination of the serum VEGF concentration were carried out in the cooperating Laboratory of Cytometer, Department of Oncology, Hematology and Internal Medicine, Medical University of Warsaw. The samples of $2 \mathrm{ml}$ of fresh peripheral venous blood were collected from the patient on57-278 days (mean 146 days) before liver transplantation. The blood sample of every patient was processed immediately(within 1 hour) by a flow cytometer analysis.Identification of the desired cell fraction was achieved by the standard enumeration of human EPCs by surface markers expression according to the procedure indicated by Miltenyi Biotec, Germany. The sample constituted of 7 test tubes containing $100 \mu \mathrm{L}$ of fresh blood each $+40 \mu \mathrm{L}$ EPC Staining Cocktail of surface antibodies (10 $\mu \mathrm{L} \mathrm{CD} 34$ FITC BD Biosciences, $10 \mu \mathrm{L}$ CD133 PE Miltenyi Biotec, $10 \mu \mathrm{L}$ CD45 Per CP BD Biosciences and $10 \mu \mathrm{L}$ CD309 APC Miltenyi Biotec) 3 test tubes containing $100 \mu \mathrm{L}$ of fresh blood each $+40 \mu \mathrm{L}$ EPC Cocktail $(10$ $\mu \mathrm{L}$ CD34 FITC BD Biosciences, $10 \mu \mathrm{L}$ CD133 PE Miltenyi Biotec, 10 $\mu \mathrm{L}$ CD 45 Per CP BD Biosciences but $10 \mu \mathrm{L}$ Isotype Control Miltenyi Biotec) made the control. After 20 minutes of incubation, red cells were lysed with FACS Lysing Solution (BD Biosciences), incubated again for 10 minutes, rinsed in Cell Wash (BD Sciences) and pooled. Then the sampleswere consecutively analyzed by the flow cytometer FACS CANTO II (BD Biosciences) by using the multiparametric cells gating strategy according to the approval of the International Society of Hematology and Graft Engineering (ISHAGE). The results were expressed as the rate of hematopoietic stem cells defined by the 
phenotype CD34+, CD133+, CD45 dim within the amount of white blood cells (\%HSCs/WBC), and the rate of endothelial progenitor cells defined by the phenotype CD34+,133+,CD45dim,CD309+ (the cells possessing the vascular endothelial growth factor receptor-2)within thehematopoietic stem cells population (\%EPCs/HSCs).

\section{Quantitative determination of serum VEGF concentration}

Serum samples were collected from the patients prospectively. They were drawn into a serum separator and centrifuged at 3,000 rpm for 10 minutes, then stored at $-80^{\circ} \mathrm{C}$. The VEGF level was measured with an enzyme-linked immunosorbent assay kit designed to measure human VEGF serum concentration (Quantikine Human VEGF Immunoassay; R and D Systems, Minneapolis, MN, USA); $100 \mu \mathrm{L}$ recombinant human VEGF standard and serum sample were serially diluted and pipetted onto a microtiter plate coated with murine monoclonal antibody specific for human VEGF and incubated for 2 hours at room temperature.After washing, a horseradish peroxidaselinked polyclonal antibody specific for VGEF was added, and after further washing tetramethyl benzidine was added. The sensitivity of the assay was $9 \mathrm{pg} / \mathrm{mL}$, and the coefficients of variation of intra assay and interassay determination were in the range of $4.4-6.7 \%$ and $6.2-8.8 \%$, as indicated by the producer.

\section{Pathologic study}

The study was carried out in cooperation with the Department of Pathology,Medical Universityof Warsaw. The explanted livers of 49patients were examined by an expert pathologist with experience in liver cirrhosis and HCC pathology. The pathologist was unaware of the pre-operative rates of circulating HSCs and EPCs enumeration, and levels of serum VEGF concentrations. HCC on the explanted liver were staged according to the Milan criteria and graded as well, moderately and poorly differentiated according to the WHO system of classification (modified Edmondson-Steiner system). Serial sections of HCC and the surrounding liver were examined to identify the presence of a micro vascular invasion,advances in liver cirrhosis or microsatellite lesions corresponding to intrahepatic metastases.

\section{Statistical analysis}

The descriptive analysis was computed for all variables. The number of patients deceased due to procedure complications and due to advances of HCC, as well as these remaining free of malignancy and those with a tumor relapse were checked off.The data of pre-transplant clinical settings and the on-explant pathologic study, includingthe type of cirrhosis, number of lesions, HCC grading, architecture andmicro vascularinvasion were collected. The quantitative data of pre-transplant rates of HSCs/WBC and EPCs/HSCs, as well asserum VEGF concentration were expressed as mean \pm SD and median $95 \%$ CI. The data were compared between the groups categorized by the relapseof HCC before 36 and 54 months of follow-up and analysed by Kruskal-Wallis one-way of variance.Correlation between continuous variables was also estimated with the Spearman correlation coefficient. The multivariate analysis (logistic analysis of regression-Wald test, Program Statistica-10) was performed to assess factors associated with HCC recurrence by evaluating the incidence of HCC relapses between groups categorized by liver pathology andHCCclinic-pathologic characteristic (type of cirrhosis, number of lesions, HCC grading, architecture and microvascular invasion, pre-transplant level of AFP andplatelets count (PLT), rate of hematopoietic stem cells (\%HSCs/ WBC), rate of endothelial progenitor cells (\%EPCs/HSCs), and serum VEGF concentration. Results with a p-value of less than 0.05 were considered as statistically significant.

\section{Results}

There were 49 patients with HCC that were selected for the study and transplanted in 2009.The post-transplant complications resulted in death occurred in 9 (18.4\%) patients (F.4. M.5, median age 57 years); 6 (66.6\%) had liver cirrhosis related to HCV infection (4 of them with the component of ALD), and 3 (33.4\%) had liver cirrhosis related to HBV infection; 3 were in class A and 6in class B of Child-Pugh Classification. The pre-transplant median serum alpha-fetoprotein (AFP) level in this group was $92.45 \mathrm{ng} / \mathrm{mL}(\mathrm{SD} \pm 82.54)$, median 144.4 (28.95-155.84 $95 \% \mathrm{CI}$ ) and the platelets count (PLT) was $54.5 \times 10^{3} / \mathrm{mcL}, \mathrm{SD} \pm 23.08$, median $38.0 \times 10^{3} / \mathrm{mcL}\left(36.8-72.3 \times 10^{3} 95 \% \mathrm{CI}\right)$. The explant analysis indicated solitary lesion in $5(55.6 \%)$ and multifocal lesion in $4(44.4 \%)$; well differentiated in $3(33.4 \%)$, moderate in $5(55.6 \%)$ and poor in 1 (11\%). Micro vascular invasion of the tumor was present in 1 of them (11\%). The pre-transplant rate of hematopoietic stem cells (\%HSCs/ WBC) was 0.014 (SD \pm 0.005$)$, median 0.015 (0.0104-0.0182 95\% CI); the rate of endothelial progenitor cells (\%EPCs/HSCs) was 3.249 (SD $\pm 0.72)$, median 2.985 (2.695-3.80 95\% CI); the level of serum VEGF concentration was $423.1(\mathrm{SD} \pm 245.3)$, median 411.3 (234.55-611.68 95\% CI). Of the 9 patients, 6 (12.2\%) died within 1-4 months after transplantation due to surgical complications, sepsis and liver failure and $3(6.1 \%)$ within 10-12 month for cardiovascular complications and renal failure. The absence of the malignancy was confirmed in all of them on autopsy.

Of the 40 remained patients, $11(27.5 \%)$ patients had HCC recurrence and $29(72.5 \%)$ remain free of disease.

The time elapsed from the procedure to the detection of the new lesion in 11 patients with HCC recurrence ranged from 9 to 52 months, with the median being 27 months. The tumor relapsed before 36 monthsin 6 (15\%) patients ( $11, \mathrm{M} 5$, median age 56 years). Theywere transplanted for HCC in the cirrhotic liver related to HCV infection, with the component of ALD in 4; 3 were in class A, and 3 in class B of Child-Pugh classification. The pre-transplant median serum alphafetoprotein (AFP) level in this group was $9470.5 \mathrm{ng} / \mathrm{mL}$ (SD \pm 4446.5 ), median 6869 (562.7-10490.5 95\% CI), and the platelets count (PLT) was $74.0 \times 10^{3} / \mathrm{mcL}(\mathrm{SD} \pm 14,58)$, median $76.5\left(58.6-89.31 \times 10^{3} 95 \% \mathrm{CI}\right)$ Theexplant analysis indicated multifocal lesions in all of them $(100 \%)$; in $4(66.6 \%)$ HCC was welland in $2(33.4 \%)$ moderate differentiated. Micro vascular invasion of the tumor was present in 4 (66.6\%). The pretransplant rate of hematopoietic stem cells (\%HSCs/WBC) was 0.029 ( $\mathrm{SD} \pm 0.005)$, median 0.030 (0.0244-0.03 95\% CI); the rate of endothelial progenitor cells (\%EPCs/HSCs) was 5.054 (SD \pm 1.08 ), median 5.169 (3.9166.19 95\% CI); the level of serum VEGF concentration was 313.9 (SD \pm 161.2$)$, median 331.5 (144.74-483.24 95\% CI).

The tumor relapsed after 36 months but before 54 monthsof followupin 5 (12.5\%) patients (F3, M2, median age 48 years). Four (80\%) were transplanted for HCC in the cirrhotic liver related to HCV infection (the component of ALD was present in 1 of them), and 1 (20\%) for HCC in the cirrhotic liver related to an HBV infection; 4 were in class $\mathrm{A}$, and 1 in class B of Child-Pugh classification. The pre-transplant median serum alpha-fetoprotein (AFP) level in this group was $2541.2 \mathrm{ng} / \mathrm{mL}$ $(\mathrm{SD} \pm 5506)$, median $114.4(-4295-937895 \% \mathrm{CI})$, and the platelets count (PLT) was $96.4 \times 10^{3} / \mathrm{mcL}(\mathrm{SD} \pm 78.4)$, median $61.0(-5.0-193.3$ $\times 10^{3} 95 \%$ CI). The explant analysis indicatedsolitary lesion in $3(60 \%)$ andmultifocal lesion in 2 (40\%); HCC was moderately differentiated in $2(40 \%)$ and poorly in $3(60 \%)$. Micro vascularinvasion of the tumor was present in $3(60 \%)$. The pre-transplant rate of hematopoietic stem cells (\%HSCs/WBC) was 0.019 (SD \pm 0.006$)$, median 0.015 (0.01-0.026 
Citation: Otto WJ, Hołówko WH, Krawczyk MS, Król MA, Wilkowojska UM, et al. (2015) Hcc Angiogenic Propriety and Tumor Recurrence in Liver Transplant Recipients. Pharm Anal Acta 6: 343. doi:10.4172/2153-2435.1000343

Page 4 of 8

95\% CI); the rate of endothelial progenitor cells (\%EPCs/HSCs) was 4.235 (SD \pm 0.79 ), median 4.301 (3.25-5.221 95\% CI); the level of serum VEGF concentration was 298.3 ( $\mathrm{SD} \pm 153.1)$, median 345.23 (108.13488.5 95\% CI).

Allpatients with tumor recurrence died due to advances of carcinoma before the 54th month of observation, except 1 patient who remains alive and is treated with palliative chemotherapy. Twenty nine $(72.5 \%)$ of the 40 patients ( $F 9, \mathrm{M} 29$, median age 47 years) remain free of malignancy for more than 54 months after transplantation. Twenty six (75.5\%) were transplanted for HCC in the cirrhotic liver related to an HCV infection (the component of ALD was present in 3 of them), and 7 (24.1\%) for HCC in the cirrhotic liver related to an HBV infection; 25 (86.2\%) were in class A and 4 (13.8\%) in class B of Child-Pugh classification. The pre-transplant median serum alphafetoprotein (AFP) level in this group was $473.6 \mathrm{ng} / \mathrm{mL}(\mathrm{SD} \pm 2231$ ), median $25.5(-375-132295 \% \mathrm{CI})$, and the platelets count (PLT) was $92.0 \times 10^{3} / \mathrm{mcL}(\mathrm{SD} \pm 41)$, median $78.0\left(76-107 \times 10^{3} 95 \% \mathrm{CI}\right)$. Theexplant analysis indicated solitary lesion in $19(65.5 \%)$ and multifocal lesion in 10 (34.5\%); HCC was well differentiated in 3 (10.4\%), moderatein 22 (75.8\%)and poor in $4(13.8 \%)$. Microvascular invasion was present in $3(10.3 \%)$ patients. The pre-transplant rate of hematopoietic stem cells (\%HSCs/WBC) was 0.011 (SD \pm 0.006$)$, median 0.0117 (0.01-0.018 95\% $\mathrm{CI}$ ); the rate of endothelial progenitor cells (\%EPCs/HSCs) was 3.075 ( $\mathrm{SD} \pm 0.86)$, median 3.149 (2.747-3.404 95\% CI); the level of serum VEGF concentration was $288.6(\mathrm{SD} \pm 265.8)$, median 261.98 (187.57$389.8195 \% \mathrm{CI}$ ). The patients' characteristic is presented in (Table 1).
There wasa significant differencein the pre-transplant values of serum AFP level between the 11 patients with HCC recurrence and the 29 patients remaining free of disease up to 54 months after transplantation (Chisq $=10.55, \mathrm{p}<0.005$, and Chisq $=0.94, \mathrm{p}<0.6$, respectively), as well as, between the 9 patients who died due to complications of the procedure and the 10 patients with tumor recurrence who died due to advances of HCC (Chisq=6.06, $\mathrm{p}<0.04$, and Chisq $=1.31, \mathrm{p}<0.02$, respectively). There was no significant difference in the platelets count (PLT) among patients from mentioned above groups.

\section{The one-way analysis of variance (Kruskal-Wallice test) of angiogenesis factors indicated}

a) Asignificant difference in the pre-transplant rates of hematopoietic stem cells (HSCs/WBC) between the 11 patients with HCC recurrence and the 29 patients that remain free of HCC up to 54 months after transplantation, as well as, between the 9 patients who died due to complications of the procedure and the 10 patients with tumor recurrence who died due to advancesof HCC ((Chisq $=17.25$ $\mathrm{p}<0.001$, and Chisq=15.93, $\mathrm{p}<0.001$, respectively). The data are presented in (Figure 1).

b) Asignificant difference in the pre-transplant rates of endothelial progenitor cells (EPCs/HSCs) between the patients with HCC recurrence and the 29 patients that remain free of HCC up to 54 months after transplantation, as well as between the 9 patients who died due to complications of the procedure and the 10 patients with tumor recurrence who died due to advances of HCC ((Chisq $=13.96, p<0.001$,

\begin{tabular}{|c|c|c|c|c|c|}
\hline Variables & $\begin{array}{l}\text { Pre-transplant } \\
\mathrm{N}=49(100 \%)\end{array}$ & $\begin{array}{l}\text { Deceased for } \\
\text { complications } \\
\mathrm{N}=9 / 49(18.4 \%)\end{array}$ & $\begin{array}{l}\text { Tu. relapse }<36 \mathrm{mts} \text {. } \\
\qquad \mathrm{N}=6 / 40(15 \%)\end{array}$ & $\begin{array}{c}\text { Tu. relapse }>36 \mathrm{mts} \text {. } \\
\mathrm{N}=5 / 40(12.5 \%)\end{array}$ & $\begin{array}{l}\mathrm{HCC} \text { free }>54 \mathrm{mts} . \\
\mathrm{N}=29 / 40(72.5 \%)\end{array}$ \\
\hline \multicolumn{6}{|c|}{ Demographic \& clinic-pathologic features } \\
\hline Median age & 58 & 57 & 56 & 48 & 47 \\
\hline Female & $17(34.6 \%)$ & $4(44.4 \%)$ & $1(16.6 \%)$ & $3(60.0 \%)$ & $9(31.0 \%)$ \\
\hline Male & $32(65.4 \%)$ & $5(55.6 \%)$ & $5(83.4 \%)$ & $2(40.0 \%)$ & $20(69.0 \%)$ \\
\hline HCV incl. ALD & $\begin{array}{c}38(77.5 \%) \\
\text { (12 with ALD) }\end{array}$ & $\begin{array}{c}6(66.6 \%) \\
(4 \text { with ALD) }\end{array}$ & $\begin{array}{c}6(100 \%) \\
(4 \text { with ALD) }\end{array}$ & $\begin{array}{c}4(80.0 \%) \\
(1 \text { with ALD) }\end{array}$ & $\begin{array}{l}26(76.5 \%) \\
(3 \text { with ALD) }\end{array}$ \\
\hline HBV & $11(22.5 \%)$ & $3(33.4 \%)$ & none & $1(20.0 \%)$ & $7(24.1 \%)$ \\
\hline Child-Pugh A & $35(71.4 \%)$ & $3(33.4 \%)$ & $3(50 \%)$ & $4(80.0 \%)$ & $25(86.2 \%)$ \\
\hline Child-Pugh B & $14(28.6 \%)$ & $6(66.6 \%)$ & $3(50 \%)$ & $1(20.0 \%)$ & $4(13.8 \%)$ \\
\hline Serum AFP level (ng/mL) & $\begin{array}{c}1233( \pm 3292) \\
43.7(287-217895 \% \mathrm{Cl})\end{array}$ & $\begin{array}{c}92.4( \pm 82.54) \\
144.4(28.95-155.8495 \% \mathrm{Cl})\end{array}$ & $\begin{array}{c}9470( \pm 4446) \\
6869(562-1049095 \% \mathrm{Cl})\end{array}$ & $\begin{array}{c}2541.2( \pm 5506) \\
114.4(-4295-937895 \% \mathrm{Cl})\end{array}$ & $\begin{array}{c}473.6( \pm 2231) \\
25.5(-375.2-132295 \% \mathrm{Cl})\end{array}$ \\
\hline $\begin{array}{l}\text { Platelets count } \\
\left(\times 10^{3} / \mathrm{mcL}\right)\end{array}$ & $\begin{array}{c}83.4( \pm 42.8) \\
75.0(71.1-95.795 \% \mathrm{Cl})\end{array}$ & $\begin{array}{c}54.5( \pm 23.08) \\
38.0(36.8-72.3 \\
95 \% \mathrm{Cl})\end{array}$ & $\begin{array}{c}74.0( \pm 14.58) \\
76.5(58.6-89.31 \\
95 \% \mathrm{Cl})\end{array}$ & $\begin{array}{c}96.4( \pm 78,4) \\
61.0(-5.0-193.3 \\
95 \% \mathrm{Cl})\end{array}$ & $\begin{array}{c}92.0(\mathrm{SD} \pm 41) \\
78.0(76.0-107.095 \% \mathrm{Cl})\end{array}$ \\
\hline \multicolumn{6}{|l|}{ Tumor characteristic } \\
\hline Solitary < $5 \mathrm{~cm}$. & $27(55.1 \%)$ & $5(55.6 \%)$ & none & $3(60.0 \%)$ & $19(65.5 \%)$ \\
\hline Multifocal & $22(44.9 \%)$ & $4(44.4 \%)$ & $6(100 \%)$ & $2(40.0 \%)$ & $10(34.5 \%)$ \\
\hline Good different. & $10(20.4 \%)$ & $3(33.4 \%)$ & $4(66.6 \%)$ & none & $3(10.4 \%)$ \\
\hline Moderate differ. & $31(63.3 \%)$ & $5(55.6 \%)$ & $2(33.4 \%)$ & $2(40.0 \%)$ & $22(75.8 \%)$ \\
\hline Poor different. & $8(16.3 \%)$ & $1(11 \%)$ & none & $3(60.0 \%)$ & $4(13.8 \%)$ \\
\hline $\begin{array}{l}\text { Microvascular invasion } \\
\text { present }\end{array}$ & $11(22.4 \%)$ & $1(11 \%)$ & $4(66.6 \%)$ & $3(60.0 \%)$ & $3(10.3 \%)$ \\
\hline \multicolumn{6}{|c|}{ Soluble angiogenesis factors } \\
\hline$\% H S C s / W B C$ & $\begin{array}{c}0.015( \pm 0.008) \\
0.0148(0.012-0.017 \\
95 \% \mathrm{Cl})\end{array}$ & $\begin{array}{c}0.014( \pm 0.005) \\
0.015(0.0104- \\
0.018295 \% \mathrm{Cl})\end{array}$ & $\begin{array}{c}0.029( \pm 0.005) \\
0.030(0.0244-0.0395 \% \mathrm{Cl})\end{array}$ & $\begin{array}{c}0.019( \pm 0.006) \\
0.015(0.01-0.02695 \% \mathrm{Cl})\end{array}$ & $\begin{array}{c}0.011( \pm 0.006) \\
0.0117(0.01-0.01895 \% \mathrm{Cl})\end{array}$ \\
\hline$\%$ EPCs/HSCs & $\begin{array}{c}3.468( \pm 1.08) \\
3.410(3.156-3.77995 \% \mathrm{Cl})\end{array}$ & $\begin{array}{c}3.249( \pm 0.72) \\
2.985(2.695-3.8095 \% \mathrm{Cl})\end{array}$ & $\begin{array}{c}5.054( \pm 1.08) \\
5.169(3.916-6.1995 \% \mathrm{Cl})\end{array}$ & $\begin{array}{c}4.235( \pm 0.79) \\
4.301(3.25-5.22195 \% \mathrm{Cl})\end{array}$ & $\begin{array}{c}3.075( \pm 0.86) \\
3.149(2.747-3.40495 \% \mathrm{Cl})\end{array}$ \\
\hline VEGF level (pg/mL) & $\begin{array}{c}317.4( \pm 241.9) \\
317.7(247.9-386.995 \% \mathrm{Cl})\end{array}$ & $\begin{array}{c}423.1( \pm 245.3) \\
411.3(234.55-611.6895 \% \mathrm{Cl})\end{array}$ & $\begin{array}{c}313.9( \pm 161.2) \\
331.5(144.74-483.2495 \% \mathrm{Cl})\end{array}$ & $\begin{array}{c}298.3( \pm 153.1) \\
345.23(108.13-488.595 \% \mathrm{Cl})\end{array}$ & $\begin{array}{c}288.6( \pm 265.8) \\
261.98(187.57-389.8195 \% \mathrm{Cl})\end{array}$ \\
\hline
\end{tabular}

Values are presented as $N(\%)$, mean \& median $95 \% \mathrm{Cl}$. 

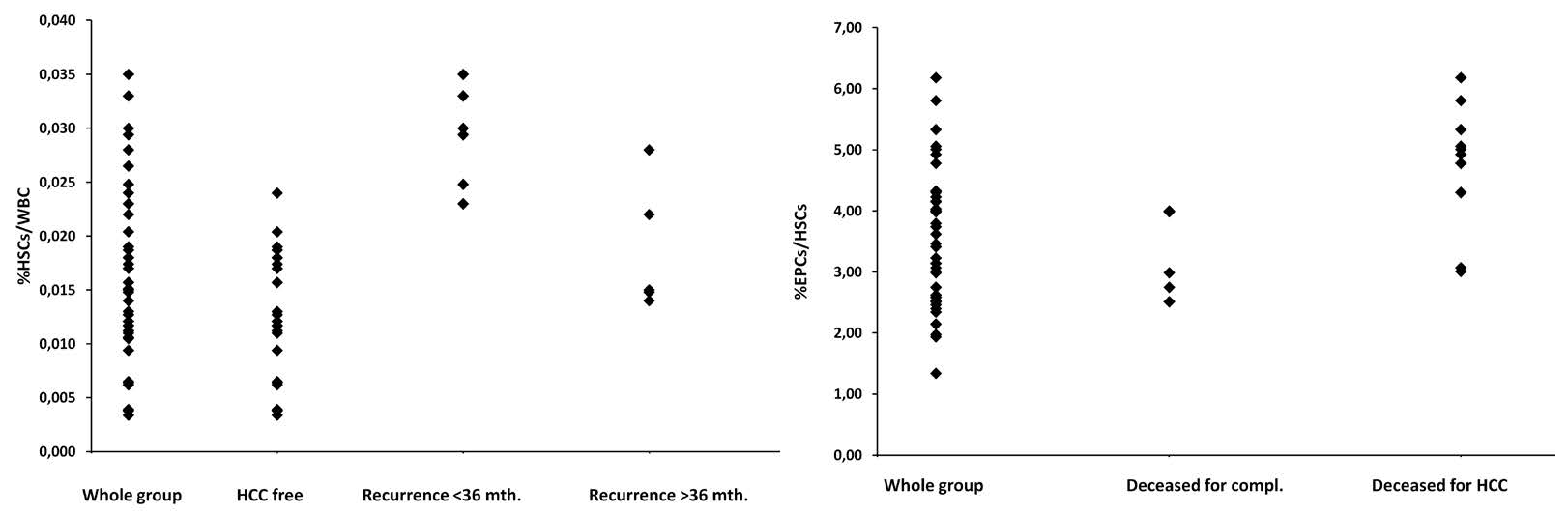

Figure 1: The pre-transplant rates of circulating hematopoietic stem cells in 49 patients transplanted for HCC within Milano criteria.
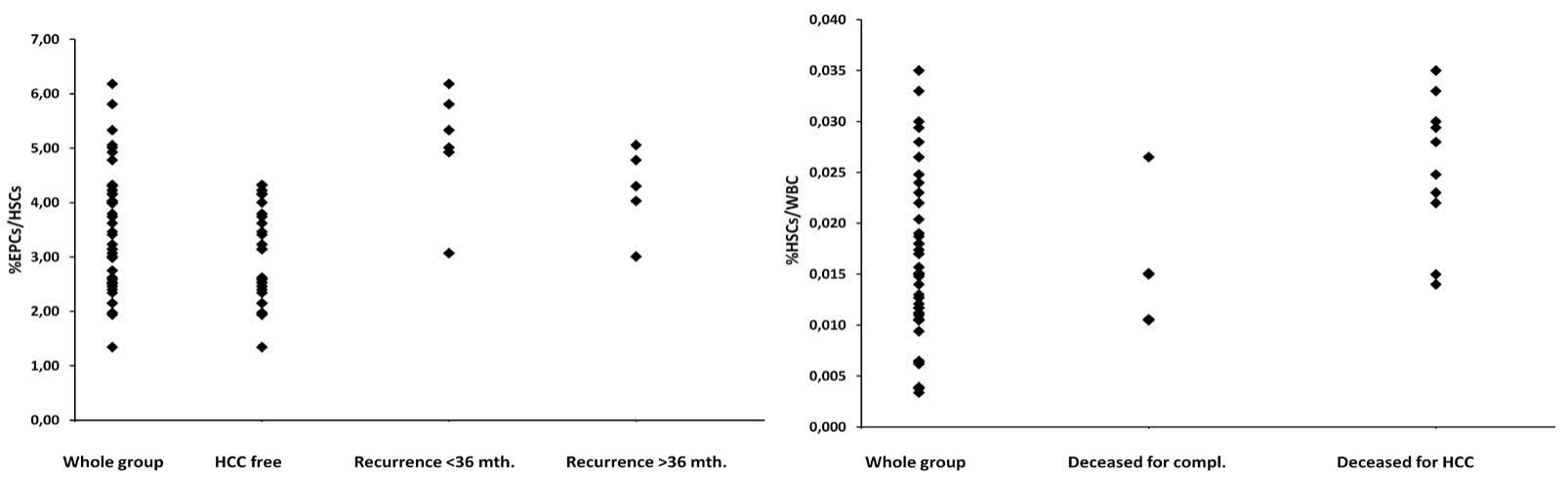

Figure 2: The pre-transplant rates of circulating endothelial progenitor cells in 49 patients transplanted for HCC within Milano criteria.

and Chisq $=14.24, \mathrm{p}<0.001$, respectively). The data are presented in (Figure 2).

There was no significant difference in the pre-transplant levels of serum VEGF concentrations between the 11 patients with HCC recurrenceand the 29 patients that remain free of HCC up to 54 months after transplantation, as well as, between the 9 patients who died due to complications of the procedure and the 10 patients with tumor recurrence who died due to advances of HCC ((Chisq $=1.43$, $\mathrm{p}<0.4$, and Chisq $=3.09, \mathrm{p}<0.2$, respectively). There wasa weak positive correlation between the level of serum VEGF concentration and the rate of platelets in the reported patients (Spearman's correlation $r=0.3$, $\mathrm{p}<0.01)$.

The multivariate logistic analysis of regression (Wald test, Program Statistica-10) indicated the grade of tumor differentiation $(\mathrm{W}=15.402, \mathrm{p}<0.001)$, the presence of microvascular invasion of the tumor to the surrounding liver tissue $(\mathrm{W}=8.179, \mathrm{p}<0.004)$, as well as the rates of circulating hematopoietic stem cells $(\mathrm{W}=7.748, \mathrm{p}<0.005)$ and endothelial progenitor cells $(\mathrm{W}=4.445, \mathrm{p}<0.035)$ as the predictor variables (features) of tumor recurrence and death due to HCCin patients with liver cirrhosis transplanted for HCC within Milan criteria.

\section{Discussion}

Extensive studies conducted by a number of centers confirm the importance of angiogenesis and vasculogenesis in HCC development and the role of newly created pathological arterial perfusion in the progress of the malignancy. Only a few studies point to the importance of hematopoietic stem cells and endothelial progenitor cells in the pre-transplant evaluation of patients with hepatocellular carcinoma, so far. Both cell fractions represent small population of blasts among the white blood cells (WBC). The hematopoietic stem cells could be recognized by the phenotype of $\mathrm{CD} 34+, 133+, 45 \mathrm{dim}$ and the endothelial progenitor cells by additional expression of the cell surface marker CD309. The combination of hematopoietic stem cells and endothelial progenitor cells is believed to be essential for HCC tumor devalopment, growth, metastasses and recurrence [18,25-27,31]. HCC cytokines, such as vascular endothelial growth factor stimulates the cell proliferation and enhances vascular permeability. Many studies have suggested that thehigh level of HSCs and EPCs and increased expression of VEGFcould associate with venous invasion and tumor recurrence in HCC [5,9,19-24,25,32,33].

Our studycovered 49 cirrhotic patients transplanted for HCC within Milan criteria. HCC recurred in 11 (27\%) of themduring 54 months of follow-up. All patients who hadHCC recurrence and who died due to HCC after the recurrence had an extremely high serum AFP level compared to the patients remaining free from the disease (Chisq=10.55, $\mathrm{p}<0.005$, and Chisq=6.06, $\mathrm{p}<0.04$, respectively). This 
confirmstheearlier reports on the significant role of the AFP level for patients' outcome or the disease monitoring $[4,7,34]$. Unfortunately, the increased level of AFP was not found to be the predictive factor of tumor recurrence in our study onmultivariate analysis. On the other hand, the analysis indicated significant differences in the pretransplant rates of hematopoietic stem cells and endothelial progenitor cells betweenpatients with HCC and those who remain free from HCC up to 54 months after transplantation (Chisq=17.25, p $<0.001$ and Chisq=13.96, $\mathrm{p}<0.001$, respectively). The significant differences in the pre-transplant rates ofboth cell fractions were alsofound between the 9 patients who died due to complications of the procedure and the 10 patients with tumor recurrence who died due to advances of HCC (Chisq=15.93, $\mathrm{p}<0.001$ and Chisq $=14.24 \mathrm{p}<0.001$, for HSCs/WBC and EPCs/HSCs respectively). Thus, the high levels of circulating progenitor cells evidenced high tumor angiogenesis propriety and appear to be the litmus test paper for recurrence predisposition. Especially, that both of the cell factors were found to be the predictor features of tumor recurrence and death due to $\mathrm{HCC}$, in patients with liver cirrhosis transplanted for HCC within Milan criteria on the multivariate logistic regression analysis $(\mathrm{W}=7.748, \mathrm{p}<0.005$ for HSCs and $\mathrm{W}=4.445$, $\mathrm{p}<0.035$ for EPCs). Both cell fractions represent the line of angiogenesis precursor cells and are in negative or positive correlation towards each other depending upon the particular situation and clinical condition [14-18]. The clinical significance of mobilized HSCs and EPCs in tumor development in HCC was proved by Sun XT et al. [30], De-cai $\mathrm{Yu}$ et al. [29], and indicated in some other reports [8-13]. Some very recent study demonstrated that the role of EPCs in neovascularization becomes more important as HCC growth progresses, and that the EPCs are mobilized and incorporated into tumor vessels throughout the whole process of HCC growth [25,27]. Although, the results were obtained in animal models of the tumor, they confirm the findings of many studies collected since the first study of the role of hematopoietic and endothelial progenitor cells was reported by Rafii et al. [15], Asahara et al. [16] and Lyden et al. [17].

Surprisingly, our study indicated no significant difference in the pre-transplant levels of serum VEGF concentrations between the 11 patients with HCC recurrence and the 29 patients that remain free fromHCC up to 54 months after transplantation, as well as, between the 9 patients who died due to complications of the procedure and the 10 patients with tumor recurrence who died due to advances of HCC ((Chisq $=1.43, \mathrm{p}<0.4$, and Chisq $=3.09, \mathrm{p}<0.2$, respectively). The VEGF is known to be the most potent angiogenesis factor and the stimulator of endothelial progenitor cells proliferation [21-23,27,28]. The association between the HCC development and the enhanced level of serum vascular endothelial growth factor concentration is indicated by numerous studies $[25,26,30,31]$. Some report also an association of the increased serumVEGF level concentration with the microvascular invasion of the tumor to the surrounding vessels $[14,20,24,27]$. The increased level of VEGD is also justified as the marker of the HCC ability to distant metastasis $[6,8,10,18]$. These findings are in contrast to the reports indicating lower-range serum VEGF levels in HCC patients that overlapped considerably the levels of non-tumor patients with liver cirrhosis. Tan et al. [22] reported no statistical difference observed in HCC patients undergoing liver transplantation between serum VEGF levels and tumor pathologic features. Poon et al. [21,27] indicated on $269 \mathrm{pg} / \mathrm{mL}$ of the median level of the VEGF concentration in patients with HCC and no significant association between preoperative serum VEGF levels and various clinical and laboratory variables. Jiang YF et al. [34] found no significant differences in the relative expression level of VEGF between patients with postoperative recurrence or metastases and the patients free from cancer.Unintentionally, the result of our study support the experience of all these who contest the axiom of the high VEGF level association with the tumor proprieties and with the course of cancer disease.The mean levels of serum VEGF concentrations in our patients $(317.4 \mathrm{pg} / \mathrm{mL}, 247.9-386.995 \% \mathrm{CI}$ in all transplanted for HCC and for $313.9 \mathrm{pg} / \mathrm{mL}, 144.74-483.2495 \% \mathrm{CI}$ in patients with tumor recurrence) correspond to the data reported in other studies [22,24,26,34]. Such observations could indicate either an inverse correlation between serum VEGF levels and various clinical and laboratory variables indicating advances of HCC or no correlation at all, as it is suggested, for instance, by Chen and his co-workers [35]. It should be noted, however, that most of the presented data on VEGF and HCC significant correlation originate from Chinese research centers, where HCC is frequently related to hepatitis B virus infection $[22,36,37]$. In our patients HCC tended to be related to HCV virus infection. Hepatitis B virus infection may induce HCC in the absence of liver cirrhosis, while in patients with $\mathrm{C}$ virus hepatitisthe cirrhosis underlies all future pathologies. The inverse correlation between hepatic arterial vascularity and the expression of the VEGF level in HCV related HCC patients was found by Kanematsu et al. [36], contrary to the experiences of Kwak et al. [19] who found a positive correlation in the study of mostly HBV related HCC patients. Kanematsu justifiedthe divergence by the substantial differences in the Japanese patient's population and in the underlying hepatic disease. Yegin et al. [20] evaluated four commonly used staging systems and assessedVEGF prognostic stratificationandfound no significant correlation between serum VEGF levels and clinic-pathologic features of the disease in early and intermediate-advanced stages. They established the serum median level of VEGF on $347.09 \mathrm{pg} / \mathrm{mL}$ that corresponds to the median level of VEGF in our patients, and found that they could stratify advanced cases by the cut-off VEGF level just above $445 \mathrm{pg} / \mathrm{mL}$. None of our patients were transplanted for advanced cancersand this might account for the contradictions in results. It should be also noticed that the serum VEGF level is influenced by the platelets count $[21,28,32,35]$. The VEGF is stored in platelets and release into the circulation when platelets are activated. Patients suitable for transplantation tend to have a low platelet count due to liver insufficiency, portal hypertension and hypersplenism. Thus, they may have lower levels of circulating VEGF $[20,24,32,33,35]$. The median platelet count we found in our patientstendedto be very low and did not exceed $92 \times 10^{3} \mathrm{mcL}$ in any of the patient groups. Notably, there was weak positive correlation between the level of serum VEGF concentration and the rate ofplatelet count in all of our transplanted patients (Spearman's rho=0.3, $\mathrm{p}<0.1$ ).

Certainly, recurrence is the most serious limitation of long-term survival after liver transplantation. The assessment of the tumor angiogenesis activity by the evaluation of the pre-transplant rate of circulating hematopoietic stem cells and endothelial progenitor cells could allow for the stratification of patients undergoing liver transplantation for HCC not only by patient/tumor-related factors, but alsoby characterizingintrinsic tumor features. The findings of our study consolidatealso the premises for the adjuvant therapy with agents inhibiting cell proliferation in transplant recipients for HCC that express high rates ofcirculating endothelial progenitor cells $[33,38]$. The study suggests also the use of mTOR inhibitors instead of CNIs inhibitors in the immunosuppressive post-transplant therapy,since CNIs drugs were found to have pro-angiogenesis activity [39-41] Unfortunately, the study concerned a limited group of 49 patients because it was not possible to find a more numerous population of the patients with HCC tumor within Milano criteria at the required period of time. This is the major limitation of our study. However, the number 
Citation: Otto WJ, Hołówko WH, Krawczyk MS, Król MA, Wilkowojska UM, et al. (2015) Hcc Angiogenic Propriety and Tumor Recurrence in Liver Transplant Recipients. Pharm Anal Acta 6: 343. doi:10.4172/2153-2435.1000343

Page 7 of 8

of patients corresponds to the number of cases presented in many other reports concerning factors of HCC recurrence. With our knowledge, this is probably the only study concerning the predictive role of tumor angiogenesis propriety for HCC recurrence in patients undergoing liver transplantation, so far.

\section{Conclusions}

The tumor angiogenesis capability contributes significantly to the tumor relapse after liver transplantation. Assessment of the pretransplant rate of circulating hematopoietic stem cells and endothelial progenitor cells might allow for better stratification of patients undergoing liver transplantation for HCC.

\section{Acknowledgment}

The authors wish to thank all cooperators from the Department of General, Transplant and Liver Surgery, the Department of Oncology, Hematology and Internal Medicine, and the Department of Pathology, Central Teaching Hospital, Medical University of Warsaw for their contribution to this project.This work was supported by the National Science Centre, Poland (Grant No. NN 40317794 [E/154]).

\section{References}

1. Tsouflas G, Curley SA, Abdala EK, Barnett MH (2013) Liver transplantation for hepatocellular carcinoma. UpToDate 1-35.

2. Chen CL, Concejero AM (2010) Liver transplantation for hepatocellular carcinoma in the world: the Taiwan experience. J Hepatobiliary PancreatSci 17: $555-558$

3. Schnitzbauer AA, Schlitt HJ, Geissler E (2011) Influence of immunosuppressive drugs on the recurrence of hepatocellular carcinoma after liver transplantation: a gap between basic science and clinical evidence. Transplantation 91 1173-1176.

4. Chan EY, Larson AM, Fix OK, Yeh MM, Levy AE, et al. (2008) Identifying risk for recurrent hepatocellular carcinoma after liver transplantation: implications for surveillance studies and new adjuvant therapies. Liver Transpl 14: 956-965.

5. Vivarelli M, Cucchetti A, Piscaglia F, La Barba G, Bolobdi L, et al. (2005) Analysis of risk factors for tumor recurrence after liver transplantation for hepatocellular carcinoma: key role of immunosuppression. Liver Transpl 11: 497-503.

6. Shah SA, Cleary SP, Wei AC, Yang I, Taylor BR, et al. (2007) Recurrence after liver resection for hepatocellular carcinoma: Risk factors, treatment, and outcomes. Surgery 141: 330-338.

7. Sotiropoulos GC, Molmenti EP, Losch C, Beckebaum CE, Broelsch CE, et al. (2007) Meta-analysis of tumor recurrence after liver transplantation for hepatocellular carcinoma based on 1,198 cases. Eur J Med Res12: 527-534.

8. Sun B, Zhang S, Zhang D, Du J, Guo H, et al. (2006) Vasculogenic mimicry is associated with high tumor grade, invasion and metastasis, and short survival in patients with hepatocellular carcinoma. Oncology Rep 16: 693-698.

9. Prager GW, Poettler M, Unseld M, Zielinski CC (2012) Angiogenesis in cancer: Anti VEGF escape mechanism. Transl Lung Cancer Res 1: 14-25.

10. Semela D, Dufour JF (2004) Angiogenesis and hepatocellular carcinoma. $J$ Hepatology 41: 864-880.

11. Blann AD, Pretorius A (2006) Circulating endothelial cells and endothelia progenitor cells: two sides of the same coin, or two different coins? Atherosclerosis 188:12-18.

12. Sieghart W, Fellner S, Reiberger T (2009) Differential role of circulating endothelial progenitor cells in cirrhotic patients with or without hepatocellular carcinoma. Dig Liver Dis 41:902-906.

13. Ho JWY, Pang RWC, Lau C, Sun CK, Yu WC, Fan ST, et al. (2006) Significance of circulating endothelial progenitor cells in hepatocellular carcinoma. Hepatology 44: 836-845.

14. Beerepoot LV, Mehra N, Vermaat JS, Zonnenberg BA, Gebbink MFGB, et al. (2004) Increased levels of viable circulating endothelial cells are an indicator of progressive disease in cancer patients. Ann Oncol 15: 139-145.

15. Rafii S, Lyden D, Lyden D, Benezra R, Hattori K, et al. (2002) Vascular and hematopoietic stem cells: novel targets for anti-angiogenesis therapy? Nat Rev Cancer 2: 826-835

16. Asahara T, Masuda H, Takahasi T, Kalka C, Pastore C, et al. (1999) Bone marrow origin of endothelial progenitor cells responsible for postnatal vasculogenesis in physiological and pathological neovascularization. Circ Rev 85: 221-228

17. Lyden D, Hattori K, Dias S, Costa C, Blaikie P, et al. (2001) Impaired recruitment of bone marrow-derived endothelial and hematopoietic precursor cells block tumor angiogenesis and growth. Nat Med 7: 1194-1201.

18. Fadini P, Baesso I, Albiero M, Sartore S, Agostini C, et al. (2008) Technical notes on endothelial progenitor cells: Ways to escape from the knowledge plateau. Atherosclerosis 197: 496-503.

19. Kwak BK, Shim HJ, Park ES, Kim SA, Coi D, et al. (2001) Hepatocellula carcinoma: correlation between vascular endothelial growth factor leve and degree of enhancement by multiphase contrast enhanced computed tomography. Invest Radiol 36: 487-492.

20. Yegin EG, Siykhymbayew A, Eren F, Bekiroglu N, Ozdogan O (2013) Prognosis implication of serum vascular endothelial growth factor in advanced hepatocellular carcinoma staging. Ann Hepatology 12: 915-925

21. Poon RT, Ng IO, Lau C, Yu W, Yang Z, et al. (2002) Tumor microvessel density as a predictor of recurrence after resection of hepatocellular carcinoma: prospective study. J ClinOcology 20:1775-1785.

22. Tan A, Kim R, El-Gazzaz G, Menon N, Aucejo F (2012) Serum vascular endothelial growth factor level in patients with hepatocellular carcinoma undergoing liver transplantation: experience of a single Western Center. Int J Org Transplant Med 3: 42-51.

23. Kaplan RN, Riba RD, Zacharoulis S, et al. (2005) VEGFR1-positive haematopoietic bone marrow progenitors initiate the pre-metastatic niche. Nature: 438: 820-827.

24. Kaseb A, Hanball A, Cotant M, Hassan M, Wollner I, et al. (2009) Vascula endothelial growth factor in the management of hepatocellular carcinoma. Cancer 115: 4895-4906.

25. Zhu H, Shao Q, Sun X, Deng Z, Yuan X, et al. (2012) The mobilization, recruitment and contribution of bone marrow-derived endothelial progenito cells to the tumor neovascularization occur at an early stage and throughout the entire process of hepatocellular carcinoma growth. Oncolgy Rep 28: 1217-1224.

26. Yang ZF, Poon RTP (2008) Vascular Changes in Hepatocellular carcinoma The Anatomical Rec 291: 721-734.

27. Poon RT, Ng IO, Lau C, Zhu L, Yu W, et al. (2001) Serum vascular endothelia growth factor predicts venous invasion in hepatocellular carcinoma; a prospective study. Ann Surg 233: 227-235.

28. Mathonnet M, Descottes B, Valleix D (2006) VEGF in hepatocellular carcinoma and surrounding cirrhotic liver tissue. World J Gastroenterol 12: 830-831

29. Yu D, Chen J, Sun Xi-tai, Lin-yuan Z, Chun-ping J, et al. (2010) Mechanisms of endothelial progenitor cell recruitment into neo-vessels in adjacent non-tumor tissues in hepatocellular carcinoma. BMC Cancer 10: 435-445.

30. Sun X, Yuan X, Zhu H, Deng Z, Yu D, Zhou X (2012) Endothelial precurso cells promote angiogenesis in hepatocellular carcinoma. W J Gastroenterol 18 : 4925-4933

31. Otto W, Król M, Maciaszczyk M, Sierdziński J, Najnigier B, et al. (2013) Identification and significance of circulating endothelial progenitor cells in patients with hepatocellular carcinoma. Nowotwory J Oncology 63:383-394

32. Shim J, Park J, Kim J, An M, Kong S, Nam B et al (2008) Association between increment of serum VEGF level and prognosis after transcatheter arteria chemoembolization in hepatocellular carcinoma patients. Cancer Sci 99: 2037-2044.

33. Villanueva A, Llovet JM (2005) Targeted therapies for hepatocellular carcinoma Gastroenterol 140: 1410-1426.

34. Jiang Y, Yang ZH, Hu JQ (2000) Recurrence or metastasis of HCC: predictors early detection and experimental antiangiogenic therapy. W J Gastroentero 6:61-65

35. Chen C-H, Chang L-T, Tung W-C, Chen Y-L, Chang C-L, et al. (2012) Levels and values of circulating endothelial progenitor cells, soluble angiogenic factors, and mononuclear cell apoptosis in liver cirrhosis patients. J Biomed Scien 19: 66-77. 
Citation: Otto WJ, Hołówko WH, Krawczyk MS, Król MA, Wilkowojska UM, et al. (2015) Hcc Angiogenic Propriety and Tumor Recurrence in Liver Transplant Recipients. Pharm Anal Acta 6: 343. doi:10.4172/2153-2435.1000343

Page 8 of 8

36. Kanematsu M, Osada S, Amaoka N, Goshimi S, Kondo H, et al. (2005) Expression of vascular endothelial growth factor in hepatocellular carcinoma and the surrounding liver and correlation with MRI findings. AJR 184: 832-841.

37. Wu C, Chen Y, Ho H, Hsu Y, Kuo K, et al. (2012) Association between nucleoside analogues and risk of hepatitis $B$ virus-related hepatocellular carcinoma recurrence following liver resection. JAMA 308: 1906-1913.

38. Lee J, Kim D, Lim JH, Seo M, Yi HG, et al. (2008) Palliative chemiotherapy for patients with recurrent hepatocellular carcinoma after liver transplantation . J GastrenterolHepatol 24: 800-805.
39. Tanaka S, Arii S (2010) Current status of molecularly targeted therapy for hepatocellular carcinoma: basic science. Int J ClinOncol 15:235-241.

40. Schumacher G, Oidtman M, Ruegeberg A, Jacob D, Jonas S, et al. (2005) Sirolimus inhibits growth of human hepatoma cells alone or combined with tacrolimus, while tacrolimus promotes cell growth. W J Gastroenterol 11: 1420 1425

41. Kawahara T, Asthana S, Kneteman NM (2011) m-TOR inhibitors: what role in liver transplantation. J Hepatol 55: 1441-1451. 